\title{
STUDIES OF PLASMA PERFORMANCE AND TRANSPORT IN THE ADVANCED TOROIDAL FACILITY (ATF)*
}

G. H. Neilson, S. C. Aceto, ${ }^{1}$ E. Anabitarte, ${ }^{2}$ F. S. B. Anderson, ${ }^{3}$ G. L. Bell, ${ }^{4}$ J. D. Bell, ${ }^{5}$

R. D. Benson, ${ }^{6}$ T. S. Bigelow, B. A. Carreras, T. L. Clark, ${ }^{7}$ R. J. Colchin, E. C. Crume,

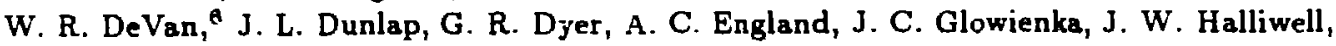

G. R. Hanson, ${ }^{8}$ J. H. Harris, C. L. Hedrick, C. Hidalgo, ${ }^{2}$ D. L. Hillis, S. Hiroe, L. D. Horton,

H. C. Howe, R. C. Isler, T. C. Jernigan, R. A. Langley, D. K. Lee, J. W. Lue, J. F. Lyon,

C. H. Ma, P. K. Mioduszewski, R. N. Morris, ${ }^{5}$ M. Murakami, D. A. Rasmussen, Ch. P. Ritz,

P. S. Rogers, ${ }^{8}$ S. W. Schwenterly, P. L. Shaw, ${ }^{7}$ T. D. Shepard, J. E. Simpkins, C. E. Thomas,

T. Uckan, M. R. Wade, ${ }^{8}$ J. A. White, ${ }^{\circ}$ J. B. Wilgen, C. T. Wilson, ${ }^{\circ}$ W. R. Wing,

H. Yamada, ${ }^{10}$ and J. J. Zielinski ${ }^{1}$

Oak Ridge National Laboratory, Oak Ridge, Tennessee $37831-8072$

\section{ABSTRACT}

An overview of recent ATF experimental results and program plans is presented, with emphasis on the role of magnetic configuration controls in transport studies. The ATF operating space is bounded by a density limit that effectively sets a limit on the energy confinement time $\tau_{E}$. Although this limit is not solely due to impurities, it has recently been raised by improved cleanliness following titanium gettering. This has led to collapse-free neutral beam injection (NBI) discharges with global $\tau_{E} \approx 16 \mathrm{~ms}$. Preliminary experiments show that stored inergy and bootstrap current are sensitive to details of the magnetic configuration.

\section{INTRODUCTION}

Since the 1960s, significant prograss has been made in both the performance and the underatanding of toroidal plaema confinement devices, primarily tokamaks and stellarators. Major steps in the development of both of these concepts are planned for the 1990s; for example, tokamaks with DT-burning plasmas, such as CIT and ITER, and stellarators with near-reactorlevel hydrogen plasma parameters, such as LHD and Wendelstein VII-X, are being designed. Despite this progress and these ambitious plans, there are still substantial gaps in the physics and technology base for toroidal confinement systems. In particular, the need for a better understanding of anomalous transport has lately received considerable attention in the U.S. fusion program.

The Adranced Toroidal Facility (ATF) [1], a continuous-coil, moderate-aspect-ratio $(R / \bar{a}=7.8)$ torsatron, was designed to investigate advances that could point the way to an optimum toroidal system. A stellarator variant was chosen for ATF in part because of the high degree of control over key properties of the magnetic configuration that it provides. This capability is central to investigations of fur.damental toroidal physics mechanisms (relevant to both tokamaks and stellarators) that are now under way: beta self-stabilization of resistive interchange modes (" $\mathrm{sec}$ ond stability"), effects of field errors, bootstrap current, and trapped electron turbulence. This paper briefly summarizes the ATF plans and the results to date in some of these arcas, highlighting the role of magnetic controls. Studies of plasma performance, density limits, and edge turbulence are also discussed.

The ATF has a major radius $R_{0}$ of $2.1 \mathrm{~m}$, an average minor radius $\bar{a}$ of $0.27 \mathrm{~m}$, and a maximum magnetic field on axis $B_{0}$ of $2 \mathrm{~T}$. For the experiments reported here, up to $200 \mathrm{~kW}$ of $53-\mathrm{GHz}$ electron cyclotron heating (ECH) system is used for plasma initiation, and up to $1.4 \mathrm{MW}$ of tangential NBI provides bulk heating. The device is an $l=2, m=12$ torsatron; in the standard configuration the rotational transform $(t)$ varies

"Restirch sponsored by the Office of Fusion Energy, U.S. Department of Energy, under contract DE-AC05-84OR21400 with Martin Marietta Energy Systems, Ine.

${ }^{1}$ Rensalaer Polytechnic Institute, New Yor't.

${ }^{2}$ CIEMAT, Madrid Spain.

${ }^{3}$ University of Wisconsin, Madison.

${ }^{4}$ Auburn University, Auburn, Alabama.

${ }^{5}$ Computing and Telecommunications Division, Martin Marietıa Energy Systems, Inc.

${ }^{6}$ Engineering Division, Martin Marietta Energy Systems, Inc.

${ }^{7}$ University of Tennessce, Knoxville.

${ }^{8}$ Georgia Institate of Technology, Atlanta.

${ }^{9}$ University of Texas, Austin.

${ }^{10}$ Nagoya University, Nagoya, Japan.

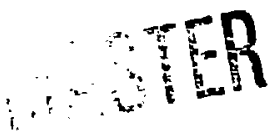


from 0.3 at the center to 1.0 at the edge, and a moderate magnetic well extends out to about th: $t=1 / 2$ surface. The maguretic field is provided by the system of coils shown in cross section in Fig. 1. The main field is provided by the two helical field (HF) coils and the four sections of the outer vertical field (VF) coils labeled "main VF," which are driven in series. Configurational flexibility is provided by the three independently driven pairs of VF coils, labeled "inner," "mid," and "trim," which control variations in the poloidal flux and in the axisymmetric dipole and quadrupole fields about the standard ATF configuration [2]. The poloidal flux can be used to inductively drive toroidal current, and the dipole and quadrupole fields control the plasma shape, stability of various modes, and trapped particle confinement.

\section{PLASMA PERFORMANCE}

The plasma is formed with either second harmonic $\mathrm{ECH}$ at $B_{0}=0.95 \mathrm{~T}$ or fundamental ECH at $B_{0}=$
$1.9 \mathrm{~T}$. After sufficient wall conditioning by $\mathrm{H}^{+}$glow discharge cleaning and mild $\left(150^{\circ} \mathrm{C}\right)$ baking of the stainless steel vessel, ECH plasmas up to $1 \mathrm{~s}$ long, the maximum ECH pulse length applied to date, have been sustained with no impurity buildup. When neutral beam heating is applied, the density, ion temperature, and stored energy begin to rise; the electron temperature initially falls but subsequently rises as shown in Fig. 2 [3]. In this example, a plasma collapse occurred at $t=0.26 \mathrm{~s}$, characterized by a drop in the stored energy and the electron and ion temperatures, while the density continued to rise or remain constant. This collapse phenomenon, discussed further below, is the mechanism that limits the density and pulse length attainable with NBI. However, through improvements in wall conditioning (titanium gettering) and gas programming, collapse-free discharges with $250 \mathrm{~ms}$ of $1.2-\mathrm{inW} \mathrm{NBI}$, $\bar{n}_{e} \approx 6 \times 10^{1 \theta} \mathrm{m}^{-3}, T_{E} \approx 16 \mathrm{~ms}$, and $B_{0}=1.9 \mathrm{~T}$ have recently been achieved, as shown in Fig. 3. Global energy confinement times measured at the peak of the stored energy are compared with those given by the

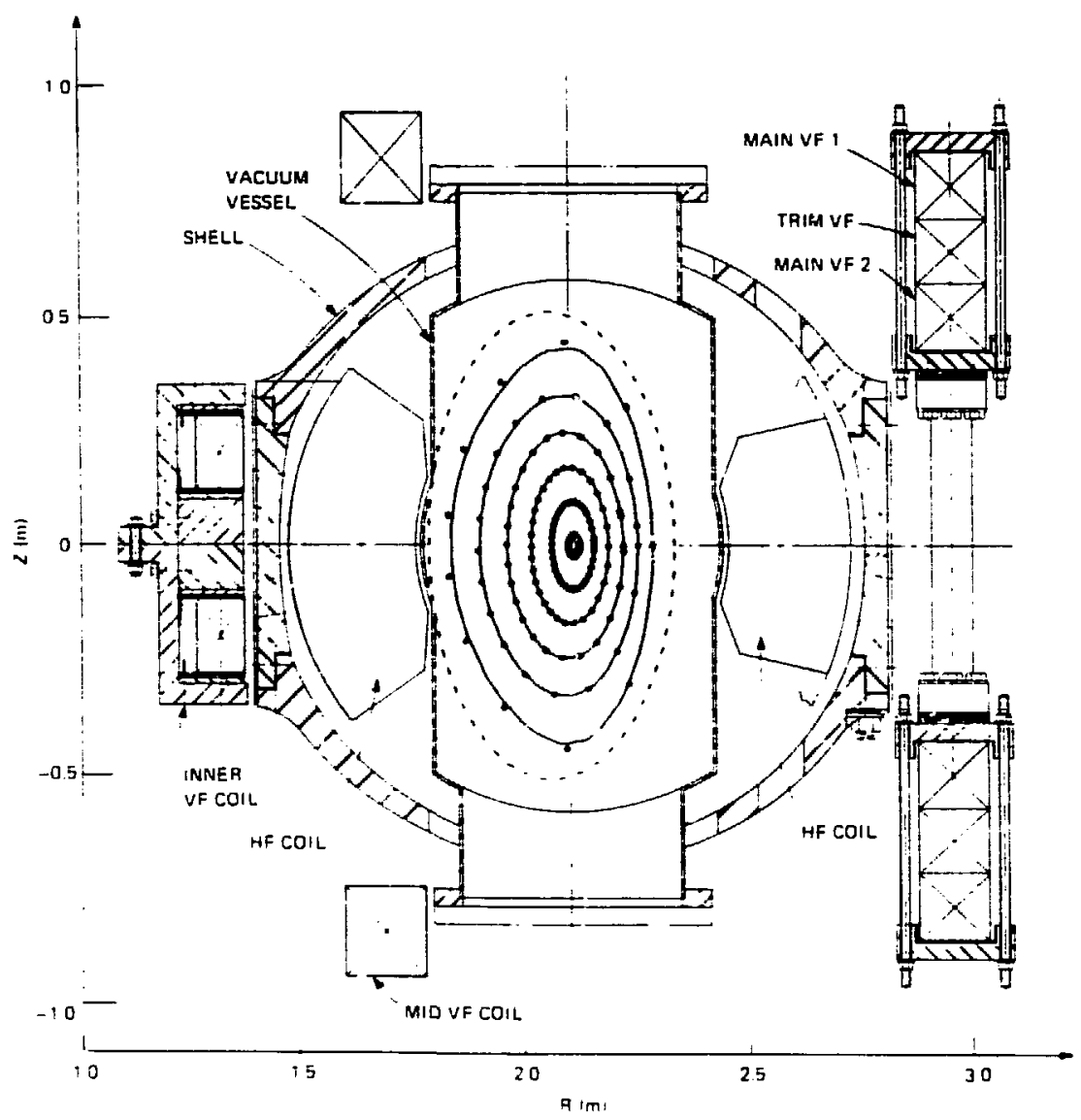

Fig. 1. Cross section of ATF showing typical magnetic surfaces and magnetic configuration control coils. 

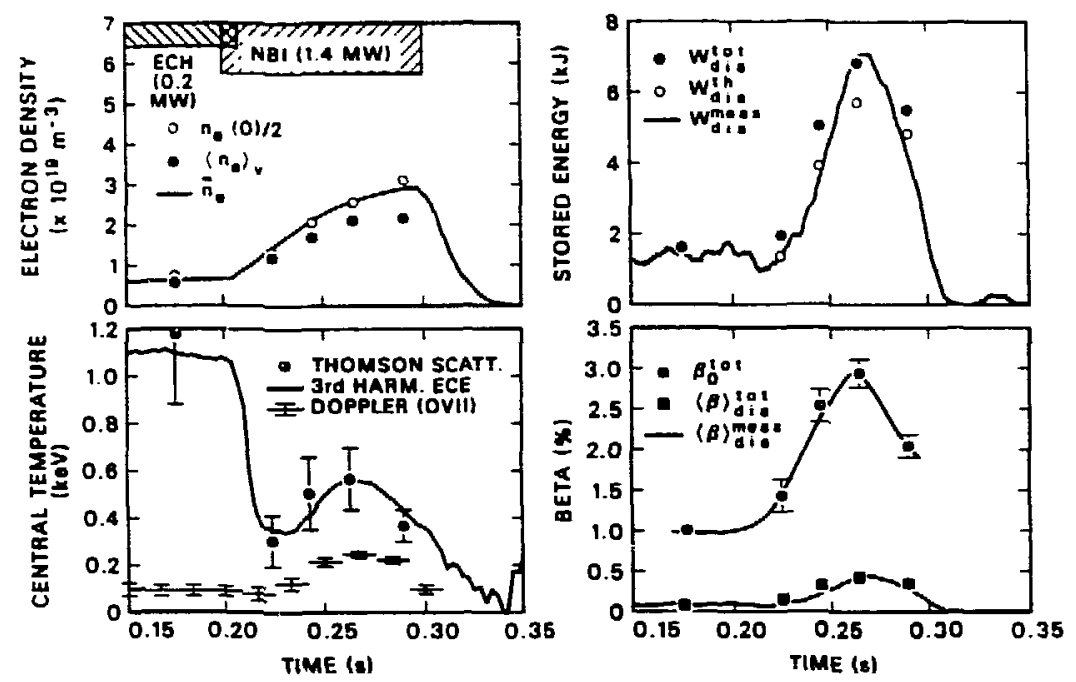

Fig. 2. ATF discharge evolution with $B_{0}=0.95 \mathrm{~T}$,

NBI heating, and limited chromium gettering.
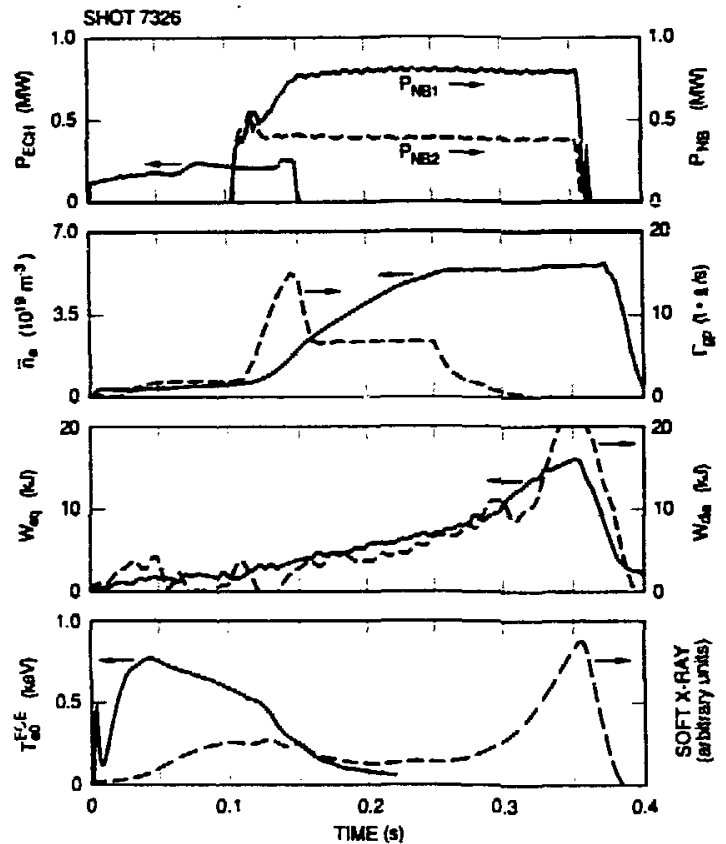

Fig. 3. ATF discharge evolution with $B_{0}=1.9 \mathrm{~T}$ after more extensive wall conditioning, including chromium gettering.

LHD sraling formula in Fig. 4. Because of the positive dependence on density, improvements in energy confinement tirne tend to accompany increases in the density limit.

Impurity behavior during NBI heating is shown in Fig. 5 ; in this example, a collapse occurred. Although increases in both the edge ( $O$ VI) and central ( $O$ VIII) impurity content are observed, they are commensurate

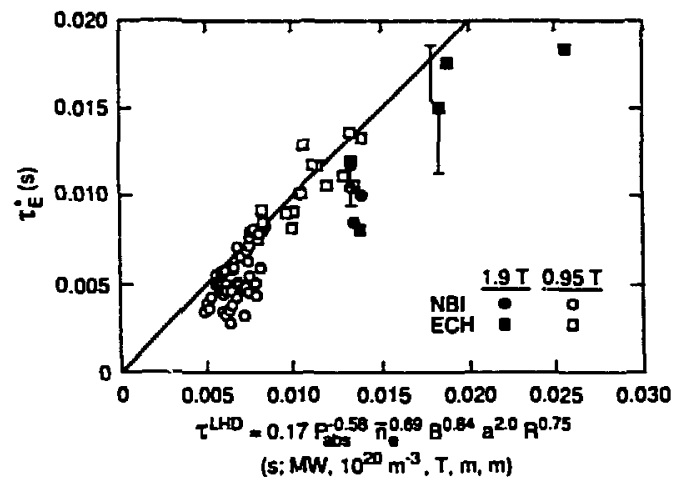

Fig. 4. Global energy confinement times in ATF compared with the LHD scaling formula, $T_{E}^{L H D}=$ $0.17 P^{-0.58} \overline{\bar{n}}_{e}^{0.69} B^{0.84} \bar{a}^{2.0} R_{0}^{0.78}$.

with the increase in the plasma density. There is little change in $Z_{\text {eff }}$ (from 1.7 to 2.1 in this example), the light impurity concentrations remain low $(1.1 \% \mathrm{O}, 1.5 \% \mathrm{C}$, $0.3 \% \mathrm{~N}$ ) through the time of collapse, and the radiated power fraction ( $\leq 40 \%$ ) is low to moderate by tokamak standards [4]. The sharp peak in the O VI aignal occurring 20-30 ms after the collapse is due to a thermal instability of the cooled plasma, which leads to the final denaity decay. However, the cause of the cooling that precipitates the collapse is unknown. Although gettering has resulted in reduced edge impurities and higher densities, compared with the nongettered case, it does not significantly affect the central impurity densities. This observation, together with the generally low impurity concentrations and radiated power levels, suggests that impurities are not solely responsible for the collapse. 


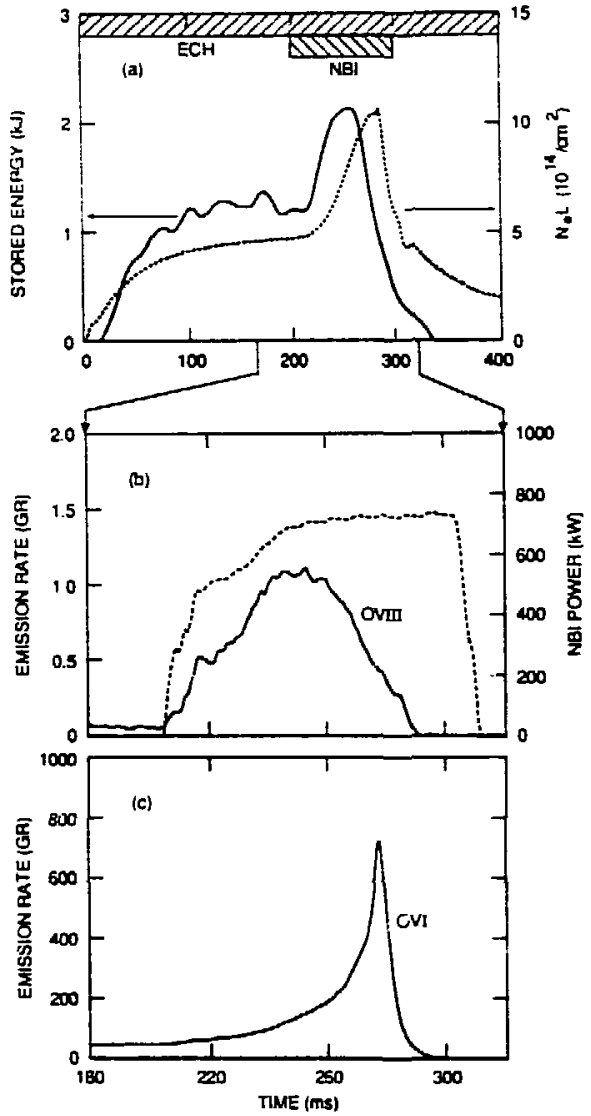

Fig. 5. Characteristics of plasma collapse. (a) Stored energy (solid) and line density (dashed). (b) Emission from O VIII impurity line, excited by charge exchange with beam neutrals (solid) and neutral beam power (dashed). (c) Emissien from O VI impurity line.

\section{TRANSPORT STUDIES}

The investigation of transport and related mechanisms as part of the U.S. Transport Initiative is currently the main focus of the ATF program. The broad objective of this effort is to contribute to the understanding of anomalous transport in toroidal devices, especially tokamaks. The controllability of the magnetic configuration makes ATF well suited for such purposes. The ATF transport stuciies can be roughly divided into three regimes: (1) the edge regime, (2) the high-beta regime, and (3) the low-collisionality regime.

\section{Edge regime}

Edge plasma parameters and electrostatic turbulence al = measured with a fast reciprocating Langmuir probe. Initial data from ECH discharges show edge electron temperatures of $\sim 20 \mathrm{eV}$, edge densities of $\sim 10^{18} \mathrm{~m}^{-3}$, and a density e-folding distance of 2$3 \mathrm{~cm}$ in the scrape-off layer. Normalized amplitudes of density fuctuations $(\bar{n} / n)$ and potential fluctuations $e \bar{\phi} / k T_{e}$ are shown in Fig. 6(a). Typically, e $\bar{\phi} / k T_{e}$ exceeds $\bar{n} / n$ by factors of $2-3$. The turbulence-driven particle flux inferred from these measurements [Fig. 6(b)] is within a factor of two of that inferred from the global particle balance; the effective diffusion coefficient is Bohm-like in magnitude. The fluctuation spectra are dominated by frequency components in the range from 40 to $200 \mathrm{kHz}$ with $k_{\perp}=1-3 \mathrm{~cm}^{-1}$. The observstions are broadly similar to those from the TEXT tokamak [5-7]. Coupling of the electrostatic turbulence to a radiative instability is expected theoretically in tokamaks [8], and a similar mechanism has been proposed for ATF. These studies, when extended to NBI-heated discharges, may shed light on the origin of the collapse phenomenon.

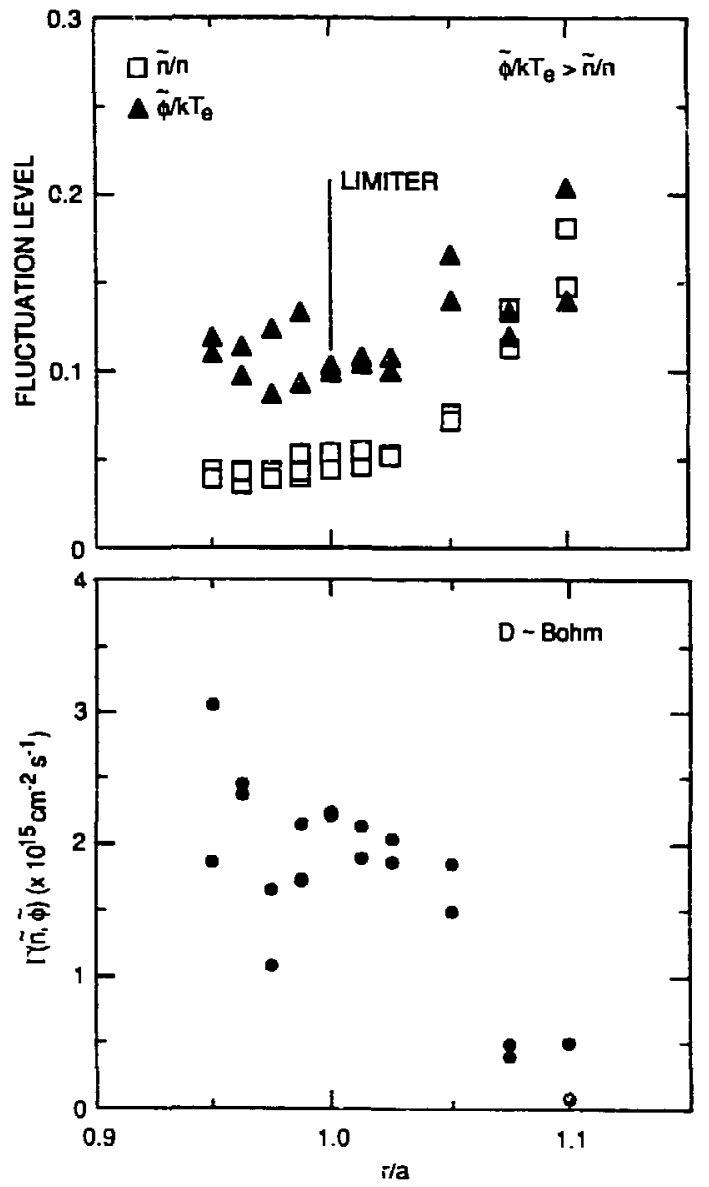

Fig. 6. Data from fluctuation measurements in the plasma edge and scrape-off regions. (a) Normalized density and posential fluctuation amplitudes. (b) Particie flux inferred from fluctuations. 


\section{High-beta regime}

Initial observations of beta self-stabilization in ATF, or entry into the second stability regime, are reported in detail in Ref. [9]. This result confirms one of the key features of the ATF magnetic design: magnetic well stabilization of the resistive interchange modes in the standard configuration [10]. The depth and radial extent of the magnetic well can be varied using the dipole field controls in ATF, providing a means of controlling the turbulence that will be tested in future studies. These modes (and their tokamak counterparts, the resistive ballooning modes) are of interest because they can cause enhanced transport [11]. Self-stabilization could therefore be a route to improved confinement and the ability to control it a means to an improved understanding of transport.

Initial scans of the dipole field (which shifts the vacuum magnetic axis) have been performed to determine the effect on global parameters. As shown in Fig. 7, the stored energy depends strongly on the magnetic configuration and reaches a maximum when the vacuum axis is shifted $\sim 1 \mathrm{~cm}$ inward from the geometric center of the coil system. (Previous results showed the peak to occur at an inward shift of $\sim 5 \mathrm{~cm}$; field errors that affected the earlier cbservations have since been corrected [12].) As outward shift corresponds to a deepening of the magnetic well and thus would be expected to stabilize curvature-driven modes such as the resistive interchange. There is no inconsistency between theory and experiment, however, since the $(\beta)$ values are most likely too low $(<0.25 \%)$ for pressure-driven turbulence to be the dominant factor in the transport. The $R_{0}$ dependence seen in Fig. 7 may be theoretically related to a reduced deviation of drift orbits from the magnetic surfaces, resulting in better fast particle confinement, when the axis is shifted in [13].

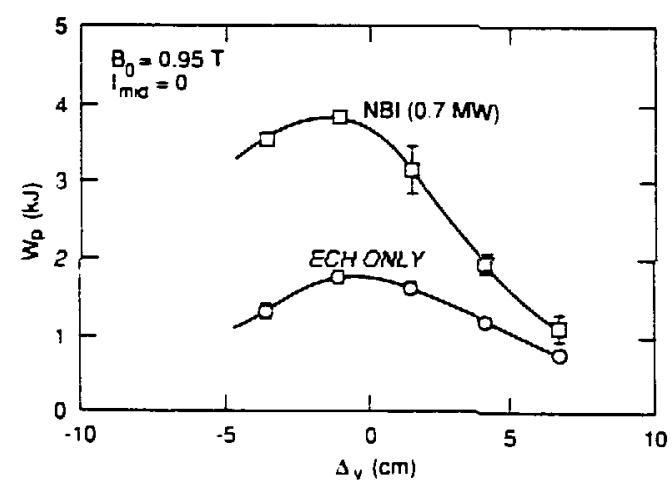

Fig. 7. Stored energy as a function of vacuum magnetic axis position in dipole field scans.
Low-collisionality regime

The bootstrap current, the trapped particle modes, and the role of electric fields in the low-collisionality $\left(\nu_{*}<1\right)$ regime will be investigated. The quadrupole field is a key control in this regime because it controls the harmonic spectrum of $|B|$ along field lines, which directly affects the bootstrap current (according to reoclassical theory) and the trapped particle confinement. The ATF js especial]y well sujted to testing theoretical models fo: the bootstrap current $\left(J_{b}\right)$ because the absence of background currents allows detection of $J_{b}$ at low levels with a simple Rogowski loop. Initial data from ECH discharges (to avoid contributions from beam-driven currents) are presented in Fig. 8. The bootstrap current varies by a factor of 5-6 as the quadrupole field is scanned using the mid-VF coils; the stored energy (not shown) also undergoes considerable variation. Neoclassical theory predicts that $J_{b} \propto G_{b} B^{-1} p^{\prime}(r)$. The dependence of the geometrical factor $G_{b}$ on the quadrupole field is consistent with Fig. 8. The dependences on magnetic field $B$ and pressure $p$ have also been checked in a rough sense and appear to be consistent with this formula as well. However, much more information is needed to make adequate comparisons of the absolute current levels and parametric dependences with theory.

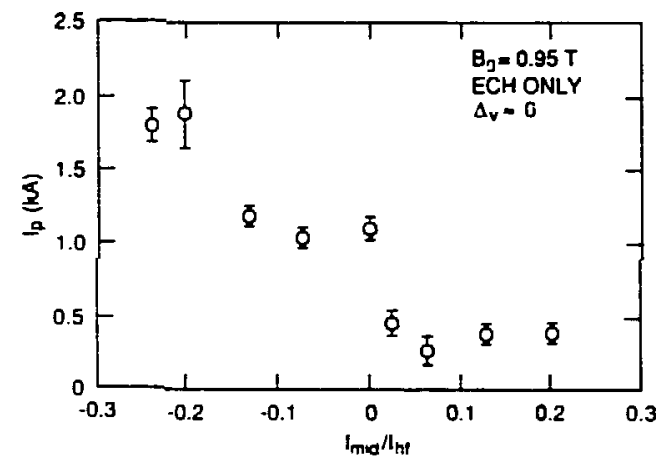

Fig. 8. Bootstrap current in ECH discharges as a function of normalized mid-VF coil current in quadrupole field scan.

\section{SUMMARY}

Stability and transport in toroidal devices are theoretically predicted to depend on detailed properties of the magnetic configuration such as field line curvature and $|B|$ spectrum. The ATF stellarator provides the degree of control needed to investigate these dependences experimentally. Initial studies confirm that global parameters such as stored energy and bootstrap current are sensitive to changes in the magnetic configuration, 
but more detailed experiments and modeling are needed to make conclusive comparisons with theory.

\section{REFERENCES}

[1] J. F. Lyon et al., Fusion Technol., vol. 10, p. 179 (1986).

[2] G. H. Neilson and J. H. Harris, Nucl. Fusion, vol. 27 , P. 711 (1987).

(3) M. Murakami et al., "Second stability studies in the ATF torsatron," in Proceedings of the 16th European Conference on Controlled Fusion and Plasma Physics, Venice, 1989, Europhysics Conference Abstrrets, Vo!. 13B, Part II, P. 575.

[4] R. C. Isler, E. C. Srume, L. D. Horton, H. C. Howe, and G. S. Voronov, Nucl. Fusion, vol. 29, P. 1381 (1989).

[5] Ch. P. Ritz et al., Nucl. Fusion, vol. 27, p. 1125 (1987).

[6] A. J. Wootton et al., Plasme Physics and Controlled Fusion, vol. 30, p. 1479 (1988).
[7] W. L. Rowan et al., Nucl. Fusion, vol. 27, p. 1105 (1987).

[8] D. R. Thayer and F. H. Diamond, Phys. Fluids, vol. 30 , p. 3724 (1987).

[9] J. H. Harris et al., Phys. Rev. Lett., vol. 63, p. 1249 (1989).

[10] B. A. Carrerss et al., Phys. Fluids, vol. 26, p. 3569 (1983).

[11] B. A. Carreras, Comments Plasma Phys. Controlled Fusion, vol. 12, p. 35 (1988).

[12] R. J. Colchin et al., "Correction of field errors in the ATF totastron," in Proceedings of the 16th European Conference on Controlled Fusion and Plasma Physics, Venice, 1989, Europhysics Conference Abstracts, Vol. 13B, Part II, p. 615.

[13] B. A. Carreras, V. E. Lynch, N. Dominguez, J. N. Leboeuf, and J. F. Lyon, Confinement Improvement of Low-Aspect-Ratio Torsations, ORNL/TM-11101, Oak Ridge National Laboratory, March 1989.

\section{DISCLAIMER}

This report was prepared as an account of work sponsored by an agency of the United States Government. Neither the United States Government nor any agency thereof, nor any of their employees, makes any warranty, express or ınplied, or assumes any legal liability or responsibility for the accuracy, completeiress, or usefu? ness of any information. apparatus, product, or process disclosed. or represents that its use would not infringe privately owned rights. Refer ence herein to any specific commercial product, process, or service by trade name, trademark, manufacturer, or otherwise does not necessarily cunstitute or imply its endorsement, recomniendation, or favoring by the United States Government or any agency thereof. The views and opinions of authors expressed herein do not necessarily state or reflect those of the United States Government or any agency thereof. 